\title{
What About the Girls? Exploring the Gender Data Gap in Talent Development
}

\author{
Orlaith Curran ${ }^{1,2}$, Aine MacNamara ${ }^{3 *}$ and David Passmore ${ }^{1}$ \\ ${ }^{1}$ School of Health and Human Performance, Dublin City University, Dublin, Ireland, ${ }^{2}$ Institute for Sport and Health, University \\ College Dublin, Dublin, Ireland, ${ }^{3}$ Institute of Coaching and Performance, University of Central Lancashire, Preston, \\ United Kingdom
}

OPEN ACCESS

Edited by: Karen Zentgraf, Goethe University Frankfurt, Germany

Reviewed by: Noora J. Ronkainen, University of Jyväskylä, Finland Yang Ge, Beijing Sport University, China

*Correspondence: Aine MacNamara amacnamara1@uclan.ac.uk

Received: 14 May 2019 Accepted: 28 June 2019 Published: 11 July 2019

Citation:

Curran O, MacNamara A and Passmore D (2019) What About the Girls? Exploring the Gender Data Gap

in Talent Development.

Front. Sports Act. Living 1:3. doi: 10.3389/fspor.2019.00003
Although there is an extensive literature about talent development, the lack of data pertaining to females is problematic. Indeed, the gender data gap can be seen in practically all domains including sport and exercise medicine. Evidence-based practice is the systematic reviewing of the best evidence in order to make informed choices about practice. Unfortunately, it may be that the data collected in sport is typically about male experiences, and not female; a rather unfortunate omission given that approximately half of the population is made up of women. When female athletes are underrepresented in research there are issues when making inferences about data collected in male dominated research domains to inform practice and policy for female athletes. In parallel, female sport participation is continually increasing worldwide. Recognizing the importance of evidence-based practice in driving policy and practice, and reflecting the gender data gap that is a consistent feature of (almost) all other domains, we were interested in examining whether a gender data gap exists in talent development research. The results suggest that a gender data gap exists in talent development research across all topics. Youth athlete development pathways may be failing to recognize the development requirements of females, particularly where female sports may be borrowing systems that are perceived to work for their male counterparts. In order to ensure robust evidence based practice in female youth sport there is a need to increase the visibility of female athletes in talent development literature.

Keywords: female athlete, youth athlete, gender gap, evidence-base, talent

\section{INTRODUCTION}

The literature base, and data, about talent development in sport is extensive and includes a range of empirical articles (Coutinho et al., 2015; Forsman et al., 2016), theory-driven papers (Phillips et al., 2010; Davids et al., 2013), and models of talent development (Gagné, 2004; Bailey and Morley, 2006) that are purported to enable researchers, practitioners, and policy makers generate a clear understanding of what is known in order to guide their practice and inform policy decisions. Indeed, across all sport science disciplines there is an understanding of the importance of evidence-based practice in determining the best outcomes for athletes and coaches. Evidencebased practice is the systematic reviewing of the best evidence in order to make informed choices about practice. Unfortunately, it may be (as elsewhere in a data-driven world) that the data collected in sport is typically about male experiences, and not female; a rather unfortunate omission given that approximately half of the population is made up of women (The World Bank, 2017)! 
The gender data gap (Perez, 2019) is important to consider against the growth of womens' and girls' sport in general and the subsequent implementation of female specific talent development pathways (e.g., The Football Association Girls' England Talent Pathway; The FA, 2017). If data is used, in the talent development space, to drive decisions about resource allocation, pathway structures, coaching, and competition about female sport, are we sure that it reflects the needs of specific populations?

There has been much recent attention on the gender data gap across domains from medicine (Vitale et al., 2017), to vehicle safety (Linder et al., 2011), and urban design (CarpioPinedo et al., 2019). Simply, researchers fail to collect data on women yet the results of research are extrapolated to females without due consideration of the impact of that transfer (Perez, 2019). When women are underrepresented in the data that underpins how decisions are made, when the statistics ignore them, the results can be problematic. For example, women are more likely to be misdiagnosed of a heart attack as they experience different symptoms to men. However, cardiac trials generally use male participants leading to the most common known symptoms of cardiac events to be those experienced by males. Similarly, cars are designed around the body and physical profile of a male, increasing the likelihood of injury to women in collisions. The dangers of not having, and using, robust data on females is farreaching.

Even when data on females is collected it is not always analyzed appropriately. As such, it is important to collect sex segregated data as "women are not just men with boobs and tubes, they have their own anatomy and physiology that deserve to be studied with the same intensity" (Mcgregor, 2015). Of course, in medicine and transportation safety the results of the data gap can be deadly (Bose et al., 2011; Linder et al., 2011; Vitale et al., 2017). In talent development, while there may not be the same catastrophic repercussions to excluding data on female experiences, failing to account for the experiences of females can result in inefficient talent systems and less than optimal experiences for female athletes. As such, closing the gender data gap requires the need to count female experiences explicitly in all fields. Sport and exercise medicine research has already been reported to significantly under-represent females in current literature, accounting for $<40 \%$ of the total number of participants (Costello et al., 2014).

The last 20 years has seen large and robust literature emerge exploring various aspects of talent development (Coutinho et al., 2016; Rongen et al., 2018; Bennett et al., 2019). This research base has focused on a broad range of factors including identifying key aspects of the talent development environment (Wang et al., 2016; Li et al., 2017; Gledhill and Harwood, 2019), the importance of psycho-behavioral factors (Höner and Feichtinger, 2016; Erikstad et al., 2018a,b; Tedesqui and Young, 2018), physiological (Arazi et al., 2013; Forsman et al., 2016; Fornasiero et al., 2018; Jones et al., 2018), coaching (Romann et al., 2017; Peña-González et al., 2018), family (Domingues and Gonçalves, 2013; Elliott et al., 2018), and early experiences (Ford et al., 2009; Schorer et al., 2010; Coutinho et al., 2015) on the trajectory of young athletes. However, if the research-practice divide is to be effectively bridged for all athletes and robust implications for practice offered to practitioners, it is important to critically examine this evidence base and its applicability for both male and female athletes. Published literature such as journal articles present the knowledge base of a given discipline and reflect the discipline's history, trends, and research norms. As such, before research findings can be applied with confidence to particular contexts, it is important to establish that the research reflects that context.

Funding and structures for women's sport is increasing across the world with the establishment of professional leagues in, for example, soccer, hockey, athletics, and talent development pathways and academy structure for young female athletes developing in parallel. Often, the structures designed for female athletes have been "borrowed" from their male counterparts, perhaps without due interrogation of the similarities and differences that may exist between the two cohorts. Recognizing the importance of evidencebased practice in driving policy and practice, and reflecting the gender data gap that is a consistent feature of (almost) all other domains, we were interested in examining whether a gender data gap exists in talent development research. Therefore, the purpose of this paper was 2-fold. Firstly, the aim of this study was to review the peer-reviewed literature in talent development published between 1999 and 2019 to examine whether female athletes were represented in the participant sampling. Building on this, the second part of the paper discusses some reasons why future studies with female athletes are important in order to ensure that the literature is reflective of commonalities and differences in their experiences.

\section{METHODS}

\section{Development of Search Strategy}

As scientist-practitioners our aim is to generate practically meaningful knowledge. As such, this study was underpinned by a pragmatic research philosophy (Giacobbi et al., 2005) and this philosophy guided all parts of the research process. This literature search utilized in this study employed review principles similar to conventional systematic reviews in order to ensure that adequate selection of literature based on replicable criteria occurred (Smith, 2010). A list of key words relevant to the aim and theme of the research was created (Smith, 2010) and these search parameters were trialed in a preliminary search on the SPORTDiscus database. During this preliminary search, every 10th result was checked and analyzed for relevance and to consider whether additional keywords should be included. This process was repeated until the most effective search terms were identified (i.e., the terms that returned the most relevant and specific literature in relation to the research question). Irrelevant terms that repeatedly came up in the search results were excluded (i.e., injury). Following this process, the final list of search terms included the following: 
"Talent Development" OR “Talent Identification" OR “Talent Selection" OR "Talent" OR "Long Term Development" OR "Specialisation" OR "Relative Age Effect" AND

"Youth Sport" OR "Youth Athlete" OR "Young Athlete" OR "Adolescence"

AND

"Maturation" OR "Growth"

AND

"Psychology" OR "Mental Skills"

NOT

"Injury"

In the final literature search two relevant databases, SPORTDiscus and Ovid, were broadly, though not exhaustively, searched using the key words in different combinations to allow for the return of relevant research papers.

\section{Inclusion/Exclusion Criteria}

Inclusion and exclusion criteria were employed to create clearly defined boundaries for the literature search (Smith, 2010). The inclusion criteria were, (a) peer reviewed empirical research studies, (b) published from January 1999 until April 2019 (when the formal search was finalized), (c) in English language, (d) have gathered original qualitative or quantitative evidence from young athletes only (under 21 years of age), and not evidence from other stakeholders (e.g., coaches, parents, peers etc.), that facilitate talent development knowledge and understanding, (e) provide information on the age and gender of the research participants, and (f) contain specific reference to either talent/talent development/talent identification/talent specialization, long term development/growth/maturation, or psychological skills/psychological attributes to talent development within the title, abstract or listed key words.

\section{Search Returns}

The search process came to a close on the 1st of April 2019 and retrieved 2,873 potentially relevant hits. Duplications were removed and abstracts and titles assessed for relevance. Based on the inclusion/exclusion criteria, 2,498 search returns were excluded and 375 papers kept for full-text retrieval. Most studies were excluded due to duplicates, a lack of definitive relevance to talent development, or their focus on senior (above 21 years of age) elite athletes. After full-text retrieval and review, 312 of the 375 papers met the inclusion criteria. Most studies were excluded due to the inclusion of coaches or parents in the participant group, no clearly defined age or gender of participants as well as inclusion of participants above 21 years. This reference list was examined by an experienced external advisory team. Suggestions from this advisory team included the removal of further studies due to a lack of definitive talent development focus as well as the suggestion for consideration of additional references. These additional studies were considered and 10 papers accessed and reviewed. Following this process an additional two references were added. Following this process, 276 studies met the inclusion criteria and were analyzed for the purpose of this review. Following the PRISMA flow diagram guidelines developed by Moher et al. (2009), an outline of the detailed overview of the search process, along with the reasons why papers were rejected, can be found in Figure 1.

\section{Data Synthesis}

The literature search was used to identify and elicit research papers regarding areas within talent development of athletes under 21 years of age. The aim of the literature search was to examine whether a gender data gap was apparent in talent development research carried out from 1999 to 2019. As a first step, the first author went through an extensive process to check all papers for relevance and identify any alternative and appropriate key words for use within the literature search to ensure accuracy and comprehensiveness. A content analysis was used to extract key information from the data regarding the gender, age and the key words used within each research paper (Pope et al., 2007).

\section{Establishing Trustworthiness}

To establish trustworthiness and meet the criteria of validity and credibility, a number of processes were followed (Creswell and Miller, 2000; Sparkes and Smith, 2009). Firstly, peer debrief, which involved a consistent review of the research process by an experienced supervisor who offered their support and criticisms, was employed (Creswell and Miller, 2000). Peer debrief took place regularly (i.e., every 2-4 weeks) through meetings and informal discussions. Secondly, an advisory team, comprised of two external researchers who had previously published studies within the explored literature, was established (Smith, 2010). The advisory team was provided with references of included studies, strategies for developing the research question, inclusion and exclusion criteria, and a briefing about the purpose of the literature search. The included papers and research methods employed were approved by the panel and suggestions for additional inclusions provided.

\section{RESULTS}

Reflecting the aims of this study, we were particularly interested in examining the participant populations included in the talent development research from 1999 to 2019. Table 1 illustrates the gender breakdown across the selected publications. Of the 276 research papers included in the data synthesis, only $9.42 \%$ included a female only population in comparison to $60.14 \%$ in a male only population, and $30.43 \%$ with both males and females included in the participant group (gender aggregated). This finding clearly indicates that a gender data gap exists in the talent development research from 1999 to 2019. Table 1 also presents the extent to which the gender aggregated research papers report findings on males and females considered together as a single participant group or if the findings were compared between the genders. $77.38 \%$ of the 84 gender aggregated papers present results where males and females have been considered separately. Of these, $86.15 \%$ illustrate a difference in the results relating to females in comparison to males.

Having established that a gender data gap was apparent, we then reviewed the results to consider whether the data gap was more or less apparent in the literature pertaining to specific 


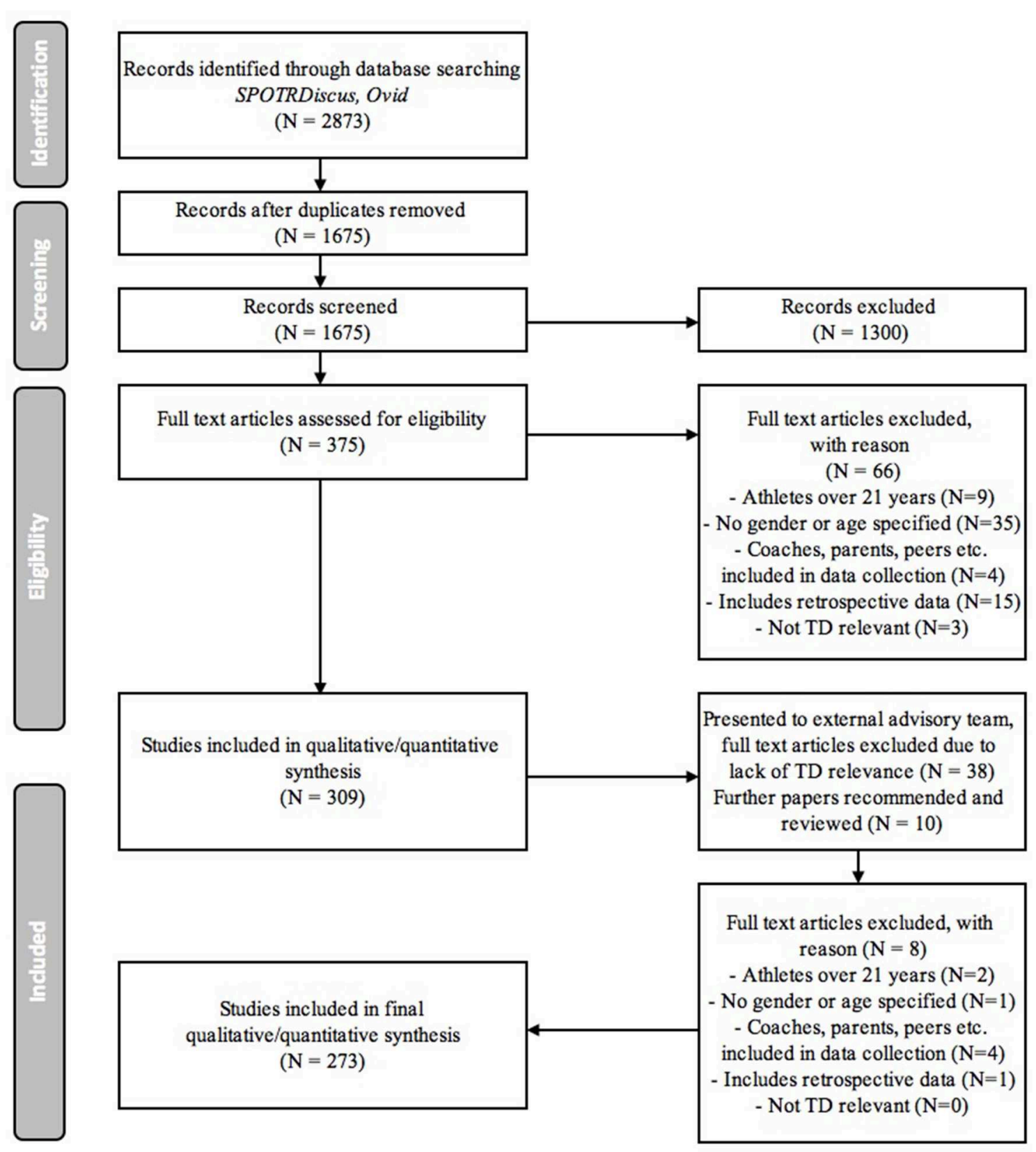

FIGURE 1 | PRISMA flow diagram of study selection.

topics in talent development (see Table 2). Research relating to the relative age effect and maturation of youth athletes was the most represented topic in the literature search (36.96\%) and, perhaps surprisingly, research relating to sport specialization (3.26\%) was the least evident. Reflecting the purpose of the paper, each topic was then analyzed to examine whether a gender data gap was apparent and this examination found that females were underrepresented across every topic. Females accounted for only $3-17 \%$ of the participant groups in the included literature compared to a $38-73 \%$ representation for male only groups.
Gender aggregated data (male and female participants) was also higher than the female only across all but one topic of the literature search. Physical factors returned $8.82 \%$ of studies for gender aggregated groups compared to $17.65 \%$ for female only groups. The gender aggregated group also accounted for less studies across all topics compared to the male only group.

Finally, we examined the data to identify trends within talent development research published from 1999 to 2019. Table 3 highlights the growth of this particular area of research in more recent years. $38.41 \%$ of the included literature were 
TABLE 1 | The number and percentage of gender groups (male, female, and gender aggregated; both male and female); and the number and percentage of papers where comparisons are made between genders represented in the research papers included in the literature search data set.

\begin{tabular}{|c|c|c|c|c|c|c|c|c|}
\hline Gender & Count & $\%$ & $\begin{array}{l}\text { Gender comparison } \\
\text { (aggregated groups) }\end{array}$ & Count & $\%$ & $\begin{array}{l}\text { Reported difference } \\
\text { between genders }\end{array}$ & Count & $\%$ \\
\hline Male & 166 & 60.14 & Yes & 65 & 77.38 & Yes & 56 & 86.15 \\
\hline Female & 26 & 9.42 & No & 19 & 22.62 & No & 9 & 13.85 \\
\hline Both & 84 & 30.43 & Total & 84 & 100.00 & Total & 65 & 100.00 \\
\hline
\end{tabular}

TABLE 2 | The number and percentage of topics and number and percentage separated per participant group represented in the research papers included in the literature search data set.

\begin{tabular}{|c|c|c|c|c|c|c|c|c|}
\hline \multirow[b]{2}{*}{ Discipline/Topic } & \multicolumn{2}{|c|}{ All } & \multicolumn{2}{|c|}{ Male } & \multicolumn{2}{|c|}{ Female } & \multicolumn{2}{|c|}{ Both $(M \& F)$} \\
\hline & Count & $\%$ & Count & $\%$ & Count & $\%$ & Count & $\%$ \\
\hline Talent development (Tactical/performance focus) & 19 & 6.88 & 14 & 73.68 & 2 & 10.53 & 3 & 15.79 \\
\hline Talent development (External to sport/environmental focus) & 21 & 7.61 & 8 & 38.10 & 3 & 14.29 & 10 & 47.62 \\
\hline Relative age effect/maturation & 102 & 36.96 & 58 & 56.86 & 8 & 7.84 & 36 & 35.29 \\
\hline Talent identification/selection & 60 & 21.74 & 42 & 70.00 & 6 & 10.00 & 12 & 20.00 \\
\hline Sport specialization & 9 & 3.26 & 6 & 66.67 & 0 & 0.00 & 3 & 33.33 \\
\hline Physical & 34 & 12.32 & 25 & 73.53 & 6 & 17.65 & 3 & 8.82 \\
\hline Psychological & 31 & 11.23 & 13 & 41.94 & 1 & 3.23 & 17 & 54.84 \\
\hline
\end{tabular}

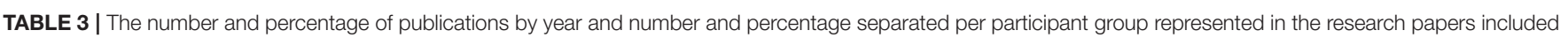
in the literature search data set.

\begin{tabular}{|c|c|c|c|c|c|c|c|c|}
\hline \multirow[b]{2}{*}{ Year of publication } & \multicolumn{2}{|c|}{ All } & \multicolumn{2}{|c|}{ Male } & \multicolumn{2}{|c|}{ Female } & \multicolumn{2}{|c|}{ Both $(M \& F)$} \\
\hline & Count & $\%$ & Count & $\%$ & Count & $\%$ & Count & $\%$ \\
\hline 2016-2019 & 106 & 38.41 & 58 & 54.72 & 8 & 7.55 & 40 & 37.74 \\
\hline 2013-2015 & 86 & 31.16 & 55 & 63.95 & 9 & 10.47 & 22 & 25.58 \\
\hline 2010-2012 & 47 & 17.03 & 28 & 59.57 & 5 & 10.64 & 14 & 29.79 \\
\hline 2007-2009 & 21 & 7.61 & 17 & 80.95 & 1 & 4.76 & 3 & 14.29 \\
\hline 1999-2006 & 16 & 5.80 & 8 & 50.00 & 3 & 18.75 & 5 & 31.25 \\
\hline
\end{tabular}

published from 2016 to 2019 compared to only $7.61 \%$ of the studies published between 2007 and 2009. Only $5.80 \%$ of the papers included in the literature search were published between 1999 and 2006. Table 3 also highlights the gender breakdown of the published papers by year and presents a clear underrepresentation of research papers with female only populations. Although attention on topics pertaining to talent development has increased year-on-year, the gender data gap has remained consistent.

\section{DISCUSSION}

The gender data gap represents an unequal representation of females across numerous domains in a world driven by data (Perez, 2019). Although there has been considerable growth in research relating to talent development in recent years, females are underrepresented in this data. Given that research should underpin advancements in real world practice in sport and youth athlete development, this gender data gap may have significant implications. Gender differences play an important role in the development of young athletes and there are notable differences between males and females in this regard; for example, physical (Batterham and Birch, 1996; Cramer et al., 2002; Weber et al., 2006; Bradley et al., 2014; Clarke et al., 2014), and cognitive (Crocker and Graham, 1995; Phillipe and Seiler, 2005; Murcia et al., 2008) differences between males and females are well-documented. Table 2 illustrates that the gender data gap is apparent across these important constructs. This becomes problematic when applying current findings to female development pathways and practices since gender can potentially influence youth athlete development. For example, the aerobic fitness evolution of young females progresses at slower rates to their male counterparts (Fornasiero et al., 2018). Furthermore, youth female athletes perceive their environment as a more task oriented climate (Murcia et al., 2008) and have a more long-term development focus than males (Li et al., 2018). Similarly, relative age effects are less pronounced in female sports, potentially due to maturational differences between females and males (Romann et al., 2018). As such, if data is to be used to inform talent development practice, there is a need for caution when making inferences about female athletes from male dominated research studies. Though beyond the scope of this review, we additionally 
recognize the complexity of these issues and the need for research to evolve further to adequately and appropriately represent individuals of all gender identities, whether they identify as men, women, or other. However, in this context we have delimited the analysis to male/female to reflect the categorization of competitive sport.

This literature search highlighted an underrepresentation of female data across all topics of talent development research and questions the extent to which the research as it stands can be extrapolated with confidence to female talent pathways. For example, there is less evidence on females in research specific to talent identification, physical and psychological development. Despite the dearth of female based talent development literature, there is continued growth worldwide of female sport, with sports participation amongst girls and women at an all-time high, female athletes are participating in record numbers (Fink, 2015). Research pertaining to male athletes cannot be assumed to relate to female athletes and the implications of applying such research findings to female sport are vast, creating talent pathways likely to be unreflective of female athlete needs.

Based on the evidence presented here, it can be hypothesized that current talent development pathways and systems for female athletes have been designed and developed based on male data. As such, talent development systems and structures for female athletes appear to lack a robust evidence base and may instead be the product of experience, gut feel, and tradition largely adopted from male athlete experiences. Simply, there is clearly a need for evidence of the experiences, requirements, and reflections of female athletes on the talent development pathway across all topics of talent development-physical, psycho-behavioral, talent

\section{REFERENCES}

Arazi, H., Faraji, H., and Mehrtash, M. (2013). Anthropometric and physiological profile of iranian junior elite gymnasts. Facta Univ. 11, 35-41.

Bailey, R., and Morley, D. (2006). Towards a model of talent development in physical education. Sport Educ. Soc. 11, 211-230. doi: $10.1080 / 13573320600813366$

Batterham, A. M., and Birch, K. M. (1996). Allometry of anaerobic performance: a gender comparison. Can. J. Appl. Physiol. 21, 48-62. doi: 10.1139/h96-005

Bennett, K. J. M., Vaeyens, R., and Fransen, J. (2019). Creating a framework for talent identification and development in emerging football nations. Sci. Med. Football 3, 36-42. doi: 10.1080/24733938.2018.1489141

Bose, D., Segui-Gomez, M., and Crandall, J. R. (2011). Vulnerability of female drivers involved in motor vehicle crashes: an analysis of US population at risk. Am. J. Public Health 101, 2368-2373. doi: 10.2105/AJPH.2011.300275

Bradley, P. S., Dellal, A., Mohr, M., Castellano, J., and Wilkie, A. (2014). Gender differences in match performance characteristics of soccer players competing in the uefa champions league. Hum. Mov. Sci. 33, 159-71. doi: 10.1016/j.humov.2013.07.024

Carpio-Pinedo, J., De Gregorio Hurtado, S., and Sanchez De Madariaga, I. (2019). Gender mainstreaming in urban planning: the potential of geographic information systems and open data sources. Plan. Theory Pract. 20, 221-240. doi: 10.1080/14649357.2019.1598567

Clarke, A. C., Presland, J., Rattray, B., and Pyne, D. B. (2014). Critical velocity as a measure of aerobic fitness in women's rugby sevens. J. Sci. Med. Sport 17, 144-148. doi: 10.1016/j.jsams.2013.03.008 identification etc. and a greater visibility of female athletes in the literature. The lack of data for females in talent development undermines the ability to understand the experiences of women and girls in sport and the constraints and opportunities they experience. Furthermore, this paper presents clear evidence that data collection in talent development is distorted by gender biases and how this negatively impacts the ability to design appropriate policies, structures, and systems for female athletes. In addition to the gender data gap, we would also argue that having no data, or poor data on issues that affect female athletes in particular is a significant issue; some issues (e.g., maturation, puberty, pregnancy, menstruation) clearly impact female athletes differently than their male counterparts and gender data would help us understand this better. In sum, there is a clear need for unbiased data in order to design talent development policies and practices-the gender data gap means that we only have a partial snapshot of the experiences and requirements of females in this space. Rigorous gender data will also allow sports to make informed decisions for females in sport and track the efficacy of talent development interventions.

\section{DATA AVAILABILITY}

The datasets generated for this study are available on request to the corresponding author.

\section{AUTHOR CONTRIBUTIONS}

OC, AM, and DP contributed to the design and implementation of the research and contributed to the final version of the manuscript. OC performed the data collection and analysis.

Costello, J. T., Bieuzen, F., and Bleakley, C. M. (2014). Where are all the female participants in sports and exercise medicine research? Eur. J. Sport Sci. 14, 847-851. doi: 10.1080/17461391.2014.91 1354

Coutinho, P., Mesquita, I., and Fonseca, A. M. (2016). Talent development in sport: a critical review of pathways to expert performance. Int. J. Sports Sci. Coach. 11, 279-293. doi: 10.1177/1747954116637499

Coutinho, P., Mesquita, I., Fonseca, A. M., and Côte, J. (2015). Expertise development in volleyball: the role of early sport activities and players' age and height. Kinesiology 47, 215-225.

Cramer, J. T., Housh, T. J., Weir, J. E., Johnson, G. O., Ebersole, K. T., Perry, S. R., et al. (2002). Power output, mechanomyographic, and electromyographic responses to maximal, concentric, isokinetic muscle actions in men and women. J. Strength Condition. Res. 16, 399-408. doi: 10.1519/00124278-200208000-00010

Creswell, J., and Miller, D. (2000). Determining validity in qualitative inquiry. Theory Pract. 39, 124-130. doi: 10.1207/s15430421tip3903_2

Crocker, P. R. E., and Graham, T. R. (1995). Coping by competitive athletes with performance stress: gender differences and relationships with affect. Sport Psychol. 9, 325-338. doi: 10.1123/tsp.9.3.325

Davids, K., Araujo, D., Vilar, L., Renshaw, I., and Pinder, R. (2013). An ecological dynamics approach to skill acquisition: implications for development of talent in sport. Talent Dev. Excell. 5, 21-34.

Domingues, M., and Gonçalves, C. E. (2013). The role of parents in talented youth sport. does context matter? Polish J. Sport Tour. 20, 117-122. doi: 10.2478/pjst-2013-0011 
Elliott, S., Drummond, M. J. N., and Knight, C. (2018). The experiences of being a talented youth athlete: lessons for parents. J. Appl. Sport Psychol. 30, 437-455. doi: 10.1080/10413200.2017.1382019

Erikstad, M. K., Høigaard, R., Johansen, B. T., Kandala, N.-B., and Haugen, T. (2018a). Childhood football play and practice in relation to self-regulation and national team selection; a study of norwegian elite youth players. J. Sports Sci. 36, 2304-2310. doi: 10.1080/02640414.2018.1449563

Erikstad, M. K., Martin, L. J., Haugen, T., and Høigaard, R. (2018b). Group cohesion, needs satisfaction, and self-regulated learning: a one-year prospective study of elite youth soccer players' perceptions of their club team. Psychol. Sport Exerc. 39, 171-178. doi: 10.1016/j.psychsport.2018.08.013

Fink, J. S. (2015). Female Athletes, Women's Sport, And The Sport Media Commercial Complex: Have We Really "Come A Long Way, Baby?". Sport Management Review, 18, 331-342. doi: 10.1016/j.smr.2014.05.001

Ford, P., Ward, P., Hodges, N., and Williams, A. M. (2009). The role of deliberate practice and play in career progression in sport: the early engagement Hypothesis. High Ability Stud. 20, 65-75. doi: 10.1080/135981309028 60721

Fornasiero, A., Savoldelli, A., Modena, R., Boccia, G., Pellegrini, B., and Schena, F. (2018). Physiological and anthropometric characteristics of top-level youth cross-country cyclists. J. Sports Sci. 36, 901-906. doi: 10.1080/02640414.2017.1346271

Forsman, H., Blomqvist, M., Davids, K., Liukkonen, J., and Konttinen, N. (2016). Identifying technical, physiological, tactical and psychological characteristics that contribute to career progression in soccer. Int. J. Sports Sci. Coach. 11, 505-513. doi: 10.1177/1747954116655051

Gagné, F. (2004). Transforming gifts into talents: the DMGT as a developmental theory. High Ability Stud. 15, 119-147. doi: 10.1080/13598130420003 14682

Giacobbi, P. R. Jr., Poczwardowski, A., and Hager, P. (2005). A pragmatic research philosophy for applied sport psychology. Sport Psychol. 19, 18-31. doi: $10.1123 /$ tsp.19.1.18

Gledhill, A., and Harwood, C. (2019). Toward an understanding of players' perceptions of talent development environments in Uk female football. J. Appl. Sport Psychol. 31, 105-115. doi: 10.1080/10413200.2017.1410254

Höner, O., and Feichtinger, P. (2016). Psychological talent predictors in early adolescence and their empirical relationship with current and future performance in soccer. Psychol. Sport Exerc. 25, 17-26. doi: 10.1016/j.psychsport.2016.03.004

Jones, B., Weaving, D., Tee, J., Darrall-Jones, J., Weakley, J., Phibbs, P., et al. (2018). Bigger, stronger, faster, fitter: the differences in physical qualities of school and academy rugby union players. J. Sports Sci. 36, 2399-2404. doi: 10.1080/02640414.2018.1458589

Li, C., Martindale, R., Wu, Y., and Si, G. (2018). Psychometric properties of the talent development environment questionnaire with chinese talented athletes. J. Sports Sci. 36, 79-85. doi: 10.1080/02640414.2017.1282619

Li, C. I., Wang, C. K. J., and Pyun, D. Y. (2017). The roles of the talent development environment on athlete burnout: a qualitative study. Int. J. Sport Psychol. 48, 143-164. doi: 10.7352/IJSP2016.47.143

Linder, A., Svenson, M., Carlsson, A., Lemmen, P., Chang, F., Schmidtt, K., et al. (2011). "Evarid - Anthropometric and biomechanical specification of a finite element dummy model of an average female for rear impact testing," in The 22nd International Technical Conference on the Enhanced Safety of Vehicles (ESV) (Washington, DC: Swedish National Road And Transport Research Institute), 11.

Mcgregor, A. (2015). Why Medicine Often Has Dangerous Side Effects For Women [Video File]. Retrieved from: https://Www.Ted.Com/Talks/Alyson_Mcgregor_ Why_Medicine_Often_Has_Dangerous_Side_Effects_For_Women (accessed May 5, 2019).

Moher, D., Liberati, A., Tetzlaff, J., and Altman, D. G. (2009). Preferred reporting items for systematic reviews and meta-analyses: the prisma statement. Ann. Int. Med. 151, 264-269. doi: 10.7326/0003-4819-151-4-200908180-0 0135
Murcia, J. A. M., Gimeno, E. C., and Coll, D. G. (2008). Relationship among goal orientations, motivational climate, and flow in adolescent athletes: differences by gender. Span. J. Psychol. 11, 181-191. doi: 10.1017/S1138741600004224

Peña-González, I., Fernández-Fernández, J., Moya-Ramón, M., and Cervell, Ó. E. (2018). Relative age effect, biological maturation, and coaches' efficacy expectations in young male soccer players. Res. Q. Exerc. Sport 89, 373-379. doi: 10.1080/02701367.2018.1486003

Perez, C. C. (2019). Invisible Women: Exposing Data Bias in a World Designed for Men. London: Chatto \& Windus.

Phillipe, R. A., and Seiler, R. (2005). Sex differences on use of associative and dissociative cognitive strategies among male and female athletes. Percept. Motorskills 101, 440-444. doi: 10.2466/pms.101.2.440-444

Phillips, E., Davids, K., Renshaw, I., and Portus, M. (2010). Expert performance in sport and the dynamics of talent development. Sports Med. 40, 271-283. doi: 10.2165/11319430-000000000-00000

Pope, C., Mays, N., and Popay, J. (2007). Synthesizing Qualitative and Quantitative Health Research: A Guide to Methods. Maidenhead: Open University Press.

Romann, M., Javet, M., and Fuchslocher, J. (2017). Coaches' eye as a valid method to assess biological maturation in youth elite soccer. Talent Dev. Excell. 9, 3-13.

Romann, M., Rössler, R., Javet, M., and Faude, O. (2018). Relative age effects in swiss talent development - a nationwide analysis of all sports. J. Sports Sci. 36, 2025-2031. doi: 10.1080/02640414.2018.1432964

Rongen, F., Mckenna, J., Cobley, S., and Till, K. (2018). Are youth sport talent identification and development systems necessary and healthy? Sports Med. Open 4, 18-18. doi: 10.1186/s40798-018-0135-2

Schorer, J., Baker, J., Lotz, S., and Büsch, D. (2010). Influence of early environmental constraints on achievement motivation in talented young handball players. Int. J. Sport Psychol. 41, 42-57.

Smith, M. (2010). Research Methods in Sport. London: Learning Matters.

Sparkes, A., and Smith, B. (2009). Judging the quality of qualitative inquiry: criteriology and relativism in action. Psychol. Sport Exerc. 10, 491-497. doi: 10.1016/j.psychsport.2009.02.006

Tedesqui, R. A. B., and Young, B. W. (2018). Comparing the contribution of conscientiousness, self-control, and grit to key criteria of sport expertise development. Psychol. Sport Exerc. 34, 110-118. doi: 10.1016/j.psychsport.2017.10.002

The FA (2017). Talent Pathway. Available online at: http://Www.Thefa.Com/ Womens-Girls-Football/England-Talent-Pathway (accessed April 30, 2019).

The World Bank (2017). Population, Female (\% Of Total). Available online at: https://Data.Worldbank.Org/Indicator/Sp.Pop.Totl.Fe.Zs (accessed April 30, 2019).

Vitale, C., Fini, M., Spoletini, I., Lainscak, M., Seferovic, P., and Rosana, G. M. C. (2017). Under-representation of elderly and women in clinical trials. Int. J. Cardiol. 232, 216-221. doi: 10.1016/j.ijcard.2017.01.018

Wang, C. K. J., Pyun, D., Y., Chunxiao, L., and Lee, M. S. (2016). Talent development environment and achievement goal adoption among korean and singaporean athletes: does perceived competence matter? Int. J. Sports Sci. Coach. 11, 496-504. doi: 10.1177/1747954116654779

Weber, C. L., Chia, M., and Inbar, O. (2006). Gender differences in anaerobic power of the arms and legs - a scaling issue. Med. Sci. Sports Exerc. 38, 1-9. doi: 10.1249/01.mss.0000179902.31527.2c

Conflict of Interest Statement: The authors declare that the research was conducted in the absence of any commercial or financial relationships that could be construed as a potential conflict of interest.

Copyright (c) 2019 Curran, MacNamara and Passmore. This is an open-access article distributed under the terms of the Creative Commons Attribution License (CC BY). The use, distribution or reproduction in other forums is permitted, provided the original author(s) and the copyright owner(s) are credited and that the original publication in this journal is cited, in accordance with accepted academic practice. No use, distribution or reproduction is permitted which does not comply with these terms. 